\title{
Kinerja Pelayanan Sarana Umum di Kawasan Permukiman Terpadu Panakukang Mas Kota Makassar Berdasarkan Pendapat Masyarakat Pengguna
}

\author{
Tytoer R.A. Bandaso ${ }^{1}$
}

Diterima : 14 November 2014

Disetujui : 28 November 2014

\begin{abstract}
With the position of the Panakukang Mas region as a center integrated settlement services, can create a basic urban problems that limited the availability of public facilities and qualified in accordance with the dynamic needs of the community with the implementation of good governance of public service. Research using quantitative methods with descriptive analysis of the availability of public facilities and public satisfaction index scoring analysis of the public services facilities. The technique of collecting data through observation and questionnaires to a unified settlement Panakukang Mas area, and a review of documents that are expected to provide an overview of service performance and the provision of public facilities in Panakukang Mas. The results show the performance of public services facilities integrated residential areas Panakukang Mas region by the user community or the average of the respondents are in the public satisfaction index score service performance from 62.51 to 81.25 or better. The quality of public infrastructure services in an integrated residential Panakukang Mas increased with good performance and focus on the location and distance to public facilities. Performance measurement showed improvement in the quality of running public services based on the needs of the provision of public infrastructure and public service standards.
\end{abstract}

Key words: services performance, public facilities

\section{ABSTRAK}

Dengan kedudukan kawasan Panakukang Mas sebagai pusat pelayanan permukiman terpadu, dapat menciptakan masalah perkotaan yang mendasar yaitu ketersediaan sarana umum yang terbatas dan berkualitas sesuai dengan dinamika kebutuhan masyarakat dengan penyelenggaraan tata pelayanan publik yang baik. Penelitian menggunakan metode kuantitatif dengan analisis deskriptif ketersediaan sarana umum dan analisis skoring indeks kepuasan masyarakat terhadap pelayanan sarana umum. Teknik pengumpulan data melalui observasi dan kuesioner kepada masyarakat penghuni kawasan permukiman terpadu Panakukang Mas, dan telaah dokumen yang diharapkan dapat memberikan gambaran kinerja pelayanan dan penyediaan sarana umum di Panakukang Mas. Hasil penelitian menunjukkan kinerja pelayanan sarana umum kawasan permukiman terpadu kawasan Panakukang Mas berdasarkan masyarakat pengguna atau responden rata-rata berada pada nilai indeks kepuasan masyarakat kinerja pelayanan 62,51 - 81,25 atau baik. Kualitas layanan sarana umum di pemukiman terpadu Panakukang Mas meningkat dengan kinerja yang baik dan fokus pada lokasi dan jarak ke sarana umum. Pengukuran kinerja menunjukkan peningkatan kualitas dalam menjalankan layanan publik berdasarkan kebutuhan penyediaan sarana umum dan standar pelayanan publik.

Kata kunci: kinerja pelayanan, sarana umum

${ }^{1}$ Satker PBL Papua, Ditjen Cipta Karya

Kontak Penulis : tytoerrab@yahoo.com 


\section{PENDAHULUAN}

Permukiman berkualitas lengkap dengan sarana dan prasarana pada hakekatnya diciptakan secara terpadu, dimana keterpaduan awalnya tidak direncanakan untuk mendukung peningkatan aktivitas ekonomi, sosial dan budaya masyarakat yang beragam sehingga membuat kebutuhan akan sarana permukiman dengan kinerja dan jangkauan pelayanan yang maksimal dari pemerintah maupun swasta juga meningkat. Kedudukan strategis kawasan Panakukang Mas sebagai pusat pelayanan dan pengembangan permukiman di Kota Makassar selain menguntungkan sebagai wajah pengembangan permukiman terpadu modern juga dapat menciptakan beban karena dalam kenyataannya terdapat masalah perkotaan yang mendasar diantaranya kualitas dan ketersediaan sarana umum yang terbatas dengan dinamika kebutuhan masyarakat serta tuntutan atas penyelenggaraan tata pemerintahan yang baik (good governance), dengan akses layanan publik berbasis kebutuhan serta distribusi yang merata memperhatikan cakupan pelayanan dan populasi. Sejalan dengan permasalahan tersebut penggunaan lahan yang ketat juga turut menentukan ruang publik kawasan untuk kualitas hidup masyarakat dalam penyediaan sarana umum yang dipengaruhi layanan yang tersedia, lokasi fasilitas umum dalam melayani pelanggan secara efisien (minimisasi biaya ke tujuan) dan efektif (maksimalisasi ketersediaan layanan), transportasi (Monkkonen, 2013).

Kinerja pelayanan publik oleh pemerintah kota Makassar memang perlu terus ditingkatkan sehingga mencapai kualitas yang diharapkan, walaupun pada kenyataannya beberapa kondisi pelayanan publik yang dilaksanakan oleh aparat pemerintah belum maksimal, banyaknya keluhan masyarakat yang disampaikan melalui media massa dapat menimbulkan citra yang kurang baik bagi pemerintah yang memiliki fungsi utama sebagai pelayan masyarakat. Belum digerakkannya pelayanan publik oleh visi dan misi sehingga berdampak pada inovasi dan kreatifitas pelayanan masyarakat, ketergantungan yang tinggi pada aturan formal (rule driven) serta budaya aparatur yang masih kurang disiplin dan tanpa inisiatif, sedangkan penyediaan sarana umum kawasan permukiman kebanyakan hanya berdasarkan standar pengembang perumahan tanpa melihat standar pelayanan minimal (Situmorang, 1994). Oleh karena itu tuntutan masyarakat atas penyelenggaraan pelayanan publik yang lebih baik harus lebih responsif, sesuai kebutuhan (basic need), transparan, lebih partisipatif, akuntabel dan kompatibel dengan perkembangan lingkungan permukiman. Dari uraian tersebut, maka pertanyaan penelitian ini adalah "sejauhmana kinerja pelayanan dan penyediaan sarana umum dikawasan permukiman terpadu Panakukang Mas Kota Makassar berdasarkan pendapat masyarakat pengguna". Oleh karena itu tujuan yang ingin dicapai adalah mengukur kinerja pelayanan dan penyediaan sarana umum pada kawasan permukiman terpadu Panakukang Mas berdasarkan masyarakat pengguna.

\section{METODE PENELITIAN}

Metode yang digunakan dalam penelitian ini adalah metode kuantitatif dengan analisis deskriptif dan analisis skoring IKM (Indeks Kepuasan Masyarakat). Pengumpulan data dalam bentuk data primer dan data sekunder. Data primer dihimpun dari observasi lapangan serta penyebaran kuesioner sebanyak 123 responden sedangkan data sekunder dari telaah dokumen dan survei ke instansi. 


\section{GAMBARAN UMUM}

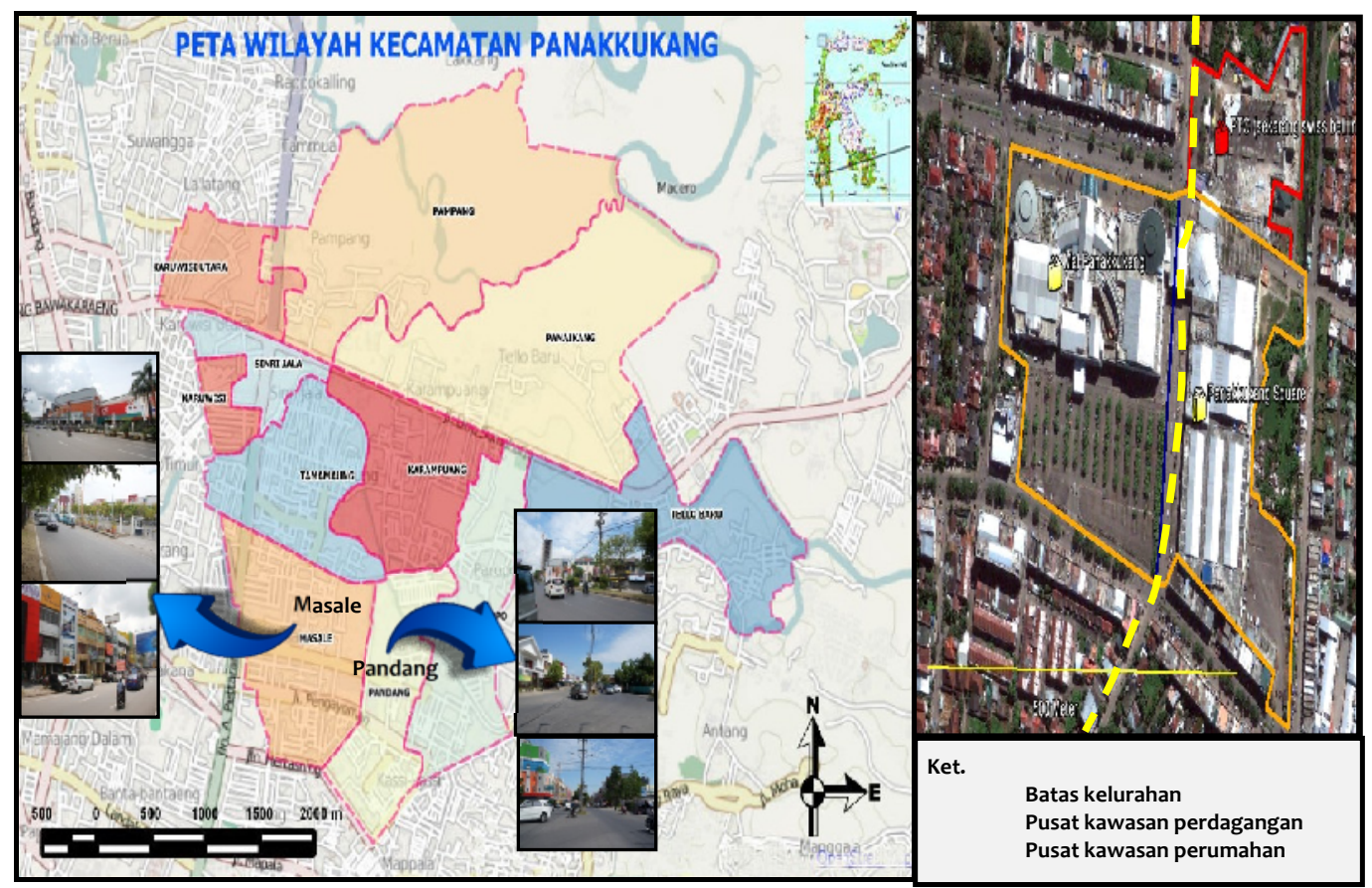

Sumber : Bappeda Kota Makassar, 2013

\section{GAMBAR 1 \\ KAWASAN PERMUKIMAN TERPADU PANAKUKANG MAS}

Kawasan permukiman terpadu Panakukang Mas secara administratif berada di Kelurahan Masale terdiri dari $31 \mathrm{RT}$, 7 RW, dengan luas wilayah 1,32 km² dan kepadatan penduduk per $\mathrm{km}^{2}$ 11.015 jiwa dan Kelurahan Pandang terdiri dari 43 RT, 7 RW, dengan luas wilayah 1,16 km² dan kepadatan penduduk per km² 10.793 jiwa.

Kawasan Panakukang Mas juga merupakan kawasan yang menghubungkan kawasan timur-barat Kota Makassar dan Kabupaten Gowa-Maros dalam simpul Mamminasata. Tipologi perumahan umumnya keluarga penghuni rumah telah tinggal lama dan mapan di kawasan Panakukang Mas, bentuk perumahan kluster dan swadaya, pemanfaatan perumahan bercampur dengan perdagangan dan jasa dengan model rumah tinggal tunggal dan deret (ruko). Pusat perdagangan tumbuh secara sporadis di kawasan ini sehingga mempengaruhi harga jual tanahnya. Kawasan Panakukang Mas menjadi kawasan ekonomi dan niaga prospektif, merupakan Central Bussines Distric terpadu. Sebagai kawasan yang didominasi area permukiman yang disertai munculnya fungsi perniagaan pada

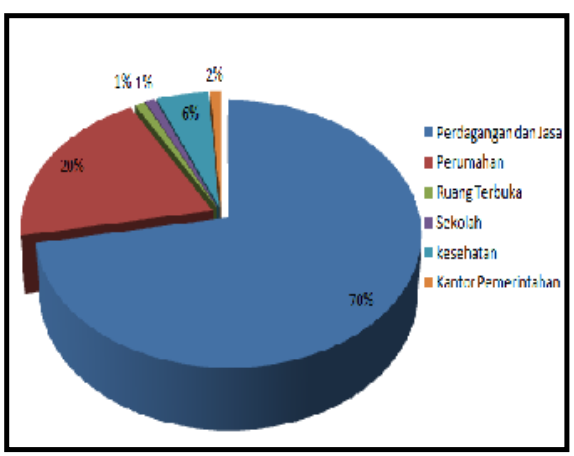

Sumber: BPS Kota Makassar, 2014

GAMBAR 2

GRAFIK PEMANFAATAN LAHAN DI PANAKUKANG MAS

hampir seluruh bagian kawasan, perubahan peruntukan lahan tidak dapat dihindari seperti jalur hijau yang menjadi tempat bermukim atau niaga dengan kepadatan bangunan (KDB 90\%) di kawasan Panakukang Mas. Jalan kawasan Panakukang Mas adalah kolektor primer dengan 
lebar jalan 16 meter dua arah menghubungkan kawasan Panakukang Mas ke jalan arteri primer kota atau pusat kota.

\section{KAJIAN TEORI}

\section{Pelayanan Sarana Umum}

Menelusuri arti pelayanan publik, Kotler (2007) menyebut pelayanan publik sebagai pelayanan dan pengelolaan yang diberikan pemerintah kepada masyarakat yang erat kaitannya dengan penggunaan barang umum (public goods) dan sarana prasarana wilayah secara merata baik kualitas dan kuantitas pelayanan.

Suryokusumo (2008), menyatakan dari sisi penyedia layanan atau pemerintah, pelayanan umum kepada masyarakat dapat dinilai dalam rangka mewujudkan pelayanan umum yang berkualitas, akuntabel, transparan, partisipatif, bertanggung jawab dalam beberapa aspek yang menjadi dasar pengukuran pelayanan publik yaitu:

- Ketersediaan (tangibilty), yaitu kualitas pelayanan yang dilihat dari penyediaan pelayanan;

- Kemampuan (reliability), yaitu kualitas pelayanan dilihat dari kelengkapan fasilitas, keterjangkauan layanan, dan kenyamanan sarana;

- Jaminan (assurance), yaitu kemampuan memberikan jaminan pelayanan dilihat dari usaha penyediaan layanan (pemerintah dan swasta) bagi masyarakat;

- Kelayakan (eligibility), yaitu suatu penilaian kelayakan kondisi sarana layanan umum dari kemampuan mengelola dan menyediakan pelayanan yang sesuai SOP.

\section{Penyediaan Sarana Umum}

Penyediaan sarana umum permukiman harus berdasarkan Standar Pelayanan Minimal. Menurut Dwiyanto (2008), indikator SPM adalah tolok ukur prestasi kuantitatif dan kualitatif yang digunakan untuk menggambarkan sasaran yang hendak dipenuhi berupa masukan, proses, hasil dan/atau manfaat pelayanan. Penetapan penyediaan sarana umum permukiman juga harus memperhatikan aksesbilitas dan lokasi sarana umum sebagai sebuah konsep kedekatan fisik. Aksesibilitas umumnya dipahami sebagai kemudahan individu dalam kegiatan melalui sistem transportasi yang tersedia dan penggunaan lahan. Aksesibilitas dalam tata ruang dan kuantitas dari tempat tinggal ke layanan terdekat (Neutensa, 2012).

\section{Kinerja Pelayanan Sarana Umum}

Kinerja dalam istilah manajemen sebagai prestasi kerja (job performance) atau prestasi nyata yang dicapai oleh seseorang (actual performance) sehingga kinerja dapat diartikan sebagai hasil kerja secara kualitas dan kuantitas yang dicapai seseorang atau sesuatu badan dalam melaksanakan tugas dan tanggung jawabnya. Menurut Nugroho (2009) untuk mengukur kinerja pelayanan umum perlu opini publik atau pendapat masyarakat mengenai berbagai masalah dimana tidak terdapat suatu pandangan yang sama.

Elis (2013) melihat pengukuran kinerja harus berkorelasi dengan sumber daya yang kita butuhkan untuk mendapatkan indikator kinerja. Pengukuran kinerja memiliki dua fungsi: menciptakan transparansi mengenai tanggung jawab kolektifitas lokal dan mendorong pembelajaran publik lokal dalam membuat langkah maju ketika menggunakan pengukuran kinerja sebagai alat untuk belajar memperbaiki pelayanan. Menurut Nugroho (2009) terdapat lima kriteria dalam mengukur dan mengevaluasi kinerja kebijakan yang dapat dijadikan alat ukur dalam pelayanan sarana umum, kriteria tersebut adalah: efektifitas, efisiensi, responsifitas, kecukupan, dan kelayakan. 
Keputusan Menpan No. Kep/25/M.PAN/2/2004 tentang Indeks Kepuasan Masyarakat (IKM), bahwa penilaian pendapat masyarakat terhadap pelayanan, melalui penyusunan indeks kepuasan masyarakat sebagai tolok ukur optimalisasi kinerja pelayanan kepada masyarakat. Untuk menentukan kinerja pelayanan diperlukan unsur pelayanan yaitu: prosedur pelayanan, persyaratan pelayanan, kejelasan petugas pelayanan, kedisiplinan petugas pelayanan, tanggung jawab petugas pelayanan, kemampuan petugas pelayanan, kecepatan pelayanan, keadilan mendapatkan pelayanan, kesopanan dan keramahan petugas, kewajaran biaya pelayanan, kepastian biaya pelayanan, kepastian jadwal pelayanan, kenyamanan lingkungan, keamanan pelayanan. Pengukuran kinerja sarana umum dengan nilai persepsi kinerja pelayanan sarana umum untuk menentukan tingkat kinerja pelayanan dalam tabel nilai persepsi kinerja pelayanan sebagai berikut:

TABEL 1 NILAI PERSEPSI KINERJA PELAYANAN SARANA UMUM

\begin{tabular}{|c|c|c|c|c|}
\hline Nilai Persepsi & Nilai Interval & Nilai Interval Konversi & Mutu Pelayanan & Kinerja Pelayanan \\
\hline 1 & $1,00-1,75$ & $25-43,75$ & D & Tidak Baik \\
\hline 2 & $1,76-2,50$ & $43,76-62,50$ & C & Kurang Baik \\
\hline 3 & $2,51-3,25$ & $62,51-81,25$ & B & Baik \\
\hline 4 & $3,26-4,00$ & $81,26-100,00$ & A & Sangat Baik \\
\hline
\end{tabular}

Sumber: Kep. Menpan, 2004

\section{Faktor-faktor yang Mempengaruhi Kinerja Pelayanan Sarana Umum}

Menurut pendapat Jones (2001), tinggi rendahnya kinerja pelayanan umum tergantung kepada faktor-faktor yang mempengaruhinya. Dalam hal ini yang menyebabkan kinerja, antara lain: 1) kemampuan pribadi; 2) kemampuan manajer, 3) kesenjangan proses; 4) masalah lingkungan; 5) situasi pribadi; 6) motivasi. Sedangkan menurut Maleki (2011), mengemukakan bahwa fokus jarak ke fasilitas dengan berjalan kaki di lingkungan perkotaan mempengaruhi layanan yang diperlukan setiap hari di permukiman. Hasil lebih lanjut, menunjukkan kepadatan, keragaman lahan, dan lapangan kerja juga dapat mempengaruhi jarak ke fasilitas.

\section{ANALISIS}

\section{Analisis Kesesuaian Sarana Umum Kawasan Panakukang Mas Terhadap Standar Pelayanan} Minimal

\section{a. Kesesuaian Jenis dan Jumlah Sarana Umum}

Kesesuaian jenis, jumlah sarana umum adalah ketersediaan jumlah sarana umum menurut jenis pelayanan sarana umum di kawasan Panakukang Mas terhadap standar pelayanan minimal yang dapat dilihat pada tabel dibawah ini:

TABEL 2

KESESUAIAN JENIS DAN JUMLAH SARANA UMUM DI PANAKUKANG MAS TERHADAP STANDAR PELAYANAN MINIMAL

\begin{tabular}{|c|c|c|c|c|}
\hline Jenis Pelayanan & $\begin{array}{l}\text { Standar Penduduk } \\
\text { (jiwa) }\end{array}$ & $\begin{array}{c}\text { Jumlah Penduduk } \\
\text { Panakukang Mas } \\
\text { (jiwa) }\end{array}$ & $\begin{array}{l}\text { Standar Jumlah } \\
\text { Sarana Umum } \\
\text { (unit) }\end{array}$ & $\begin{array}{l}\text { Jumlah Eksisting } \\
\text { Sarana Umum } \\
\text { (unit) }\end{array}$ \\
\hline \multicolumn{5}{|c|}{ Pemerintahan dan pelayanan umum } \\
\hline - $\begin{array}{c}\text { kantor } \\
\text { kelurahan }\end{array}$ & 30.000 & & 1 & 2 \\
\hline - ${ }_{\text {sektor }}$ kantor polisi & 120.000 & 21.808 & 1 & 1 \\
\hline
\end{tabular}




\begin{tabular}{|c|c|c|c|c|}
\hline $\begin{array}{r}\text { pos } \\
\text { keamanan }\end{array}$ & 2.500 & & 9 & 5 \\
\hline - $\quad$ parkir umum & 30.000 & & 1 & 3 \\
\hline kantor pos & 30.000 & & 1 & 1 \\
\hline \multicolumn{5}{|l|}{ Pendidikan } \\
\hline $\begin{array}{ll} & \mathrm{TK} \\
\end{array}$ & 1.000 & \multirow{4}{*}{21.808} & 22 & 1 \\
\hline SD & 6.000 & & 4 & 2 \\
\hline SLTP & 25.000 & & 1 & - \\
\hline - $\quad$ SLTA & 30.000 & & 1 & - \\
\hline \multicolumn{5}{|l|}{ Kesehatan } \\
\hline - $\quad$ Posyandu & 1.000 & \multirow{5}{*}{21.808} & 22 & - \\
\hline - Rumah Sakit & 10.000 & & 2 & 1 \\
\hline - $\quad$ Rumah Sakit & 240.000 & & - & 1 \\
\hline Klinik/BKIA & 10.000 & & 2 & 2 \\
\hline - ek Apotek/prakt & 5.000 & & 4 & 10 \\
\hline \multicolumn{5}{|l|}{ Perdagangan dan niaga } \\
\hline - Mall & 120.000 & \multirow{3}{*}{21.808} & - & 1 \\
\hline Pasar & 30.000 & & 1 & 1 \\
\hline - $\quad$ Toko & 250 & & 87 & 487 \\
\hline \multicolumn{5}{|l|}{ Sosial budaya } \\
\hline - ${ }_{\text {ibadah }}^{\text {Tempat }}$ & 2.500 & \multirow[t]{2}{*}{21.808} & 9 & 5 \\
\hline - $\quad$ Balai warga & 2.500 & & 9 & - \\
\hline \multicolumn{5}{|l|}{ RTH } \\
\hline - $\begin{array}{c}\text { Taman } \\
\text { lingkungan }\end{array}$ & 20.000 & 21.808 & 1 & 1 \\
\hline
\end{tabular}

Sumber: Hasil Analisis, 2014

\section{b. Kesesuaian Luas Lahan Sarana Umum Panakukang Mas terhadap Standar Pelayanan Minimal}

Kesesuaian luas lahan sarana umum adalah kesesuaian luas area sarana umum di kawasan Panakukang Mas termasuk bangunan dan lahan parkir yang ada didalamnya menurut standar pelayanan minimal. Luas lahan dapat bergantung pada lokasi sarana umum berada dan jumlah penduduk terlayani, yang dapat dilihat pada tabel dibawah ini:

TABEL 3

\section{KESESUAIAN LUAS LAHAN SARANA UMUM DI PANAKUKANG MAS TERHADAP STANDAR PELAYANAN MINIMAL}

\begin{tabular}{|c|c|c|c|}
\hline Jenis Pelayanan & $\begin{array}{l}\text { Standar Penduduk } \\
\text { (jiwa) }\end{array}$ & $\begin{array}{l}\text { Standar Luas Lahan } \\
\text { Sarana Umum }\left(\mathrm{m}^{2}\right)\end{array}$ & $\begin{array}{c}\text { Standar Luas Lahan Eksisting } \\
\text { Sarana Umum }\left(\mathrm{m}^{2}\right)\end{array}$ \\
\hline \multicolumn{4}{|c|}{ Pemerintahan dan pelayanan umum } \\
\hline $\begin{array}{l}\text { k kantor } \\
\text { kelurahan }\end{array}$ & 30.000 & 500 & $500-650$ \\
\hline $\begin{array}{l}\text { - kantor polisi } \\
\text { sektor }\end{array}$ & 120.000 & 1.000 & 1.400 \\
\hline $\begin{array}{r}\text { pos } \\
\text { keamanan }\end{array}$ & 2.500 & 12 & 6 \\
\hline - $\quad$ parkir umum & 30.000 & 100 & sepanjang kawasan \\
\hline kantor pos & 30.000 & 12 & 6 \\
\hline \multicolumn{4}{|l|}{ Pendidikan } \\
\hline - $\quad \mathrm{TK}$ & 1.000 & 1.200 & terpadu dengan SD Aloysius \\
\hline SD & 6.000 & 2.400 & 2.500 \\
\hline \multicolumn{4}{|l|}{ Kesehatan } \\
\hline - $\quad$ RS Bersalin & 10.000 & 1.600 & 2.700 \\
\hline - Umum Rumah Sakit & 240.000 & 86.400 & 19.900 \\
\hline - $\quad$ Klinik/BKIA & 10.000 & 4.000 & 600 \\
\hline - ek Apotek/prakt & 5.000 & 350 & $100-400$ \\
\hline
\end{tabular}




\begin{tabular}{|c|c|c|c|}
\hline \multicolumn{4}{|c|}{ Perdagangan dan niaga } \\
\hline - $\quad$ Mall & 120.000 & 36.000 & 70.000 \\
\hline Pasar & 30.000 & 3.000 & 9.120 \\
\hline Toko & 250 & 100 & $100-800$ \\
\hline \multicolumn{4}{|l|}{ Sosial budaya } \\
\hline - ${ }_{\text {ibadah }}^{\text {Tempat }}$ & 2.500 & 600 & $500-800$ \\
\hline \multicolumn{4}{|l|}{ RTH } \\
\hline - $\begin{array}{c}\text { Taman } \\
\text { lingkungan }\end{array}$ & 20.000 & 1.250 & 1.180 \\
\hline
\end{tabular}

\section{c. Kesesuaian Aksesbilitas Sarana Umum Panakukang Mas terhadap Standar Pelayanan} Minimal

Analisis aksesbilitas sarana umum kawasan Panakukang Mas adalah analisis untuk mengetahui jangkauan masyarakat pengguna sarana umum dari lokasi awal. Aksesbilitas sarana umum kawasan Panakukang Mas berdasarkan jarak (jangkauan ke lokasi sarana

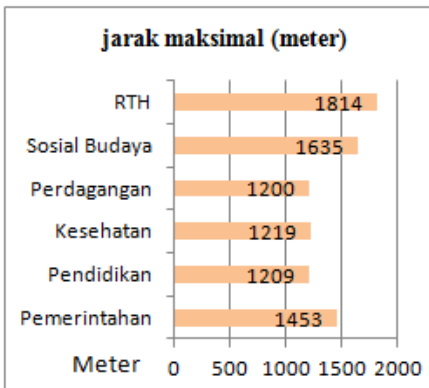

Sumber: Hosil analisis, 2014

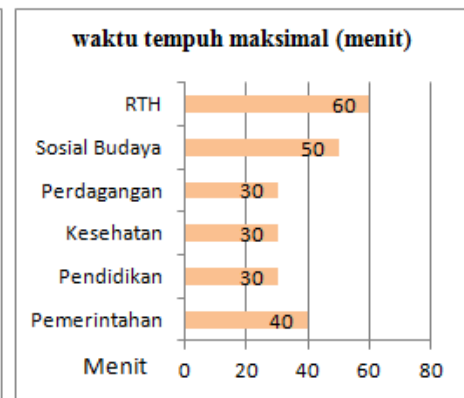

GAMBAR 1.3

JARAK DAN WAKTU TEMPUH SARANA UMUM PANAKUKANG MAS umum dari tempat semula) dan waktu tempuh (banyaknya waktu yang dibutuhkan ke tempat tujuan dengan berjalan kaki dari tempat semula). Jangkauan jarak dan waktu tempuh ke setiap jenis pelayanan sarana umum adalah dari pusat kawasan Panakukang Mas.

\section{Analisis Kinerja Penyediaan Sarana Umum Kawasan Panakukang Mas Berdasarkan Pendapat Masyarakat Pengguna}

Analisis kinerja penyediaan sarana umum merupakan analisis pengukuran kinerja pemerintah dalam penyediaan sarana umum dengan indeks kepuasan masyarakat dan pendapat responden pengguna sarana umum kawasan Panakukang Mas yang menunjukkan gambaran tingkat kepuasan masyarakat terhadap penyelenggara atau pemberi pelayanan apakah sesuai harapan dan kebutuhan masyarakat. Untuk pengukuran berdasarkan variabel penyediaan sarana umum akan dijelaskan sebagai berikut:

\section{a. Variabel Ketersediaan}

Variabel ketersediaan sarana umum mengukur tingkat kinerja penyediaan sarana umum berdasarkan indikator ketersediaan jumlah sarana umum, kecukupan akan luas lahan dan lokasi yang tepat, dan daya tampung sarana umum di kawasan Panakukang Mas. Berdasarkan hasil pengukuran kinerja variabel ketersediaan sarana umum, tingkat kepuasan masyarakat terhadap kinerja penyediaan sarana umum melalui indeks kepuasan masyarakat (IKM) variabel ketersediaan bernilai 67,61 dengan kinerja baik. Hasil pengukuran diatas menunjukkan bahwa ketersediaan sarana pemerintahan dan pelayanan umum, pendidikan, kesehatan, perdagangan dan niaga, sosial budaya, dan RTH menurut indeks kepuasan masyarakat sudah baik penyediaannya.

\section{b. Variabel Kemampuan}

Variabel kemampuan sarana umum mengukur tingkat kinerja penyediaan sarana umum dengan indikator keterjangkauan lokasi, kelengkapan fasilitas sarana umum seperti ruang 
tunggu, wc, tempat sampah, lahan parkir, dan fasilitas penunjang lainnya, dan keindahan/keserasian lingkungan sarana umum. Berdasarkan hasil pengukuran kinerja variabel kemampuan sarana umum maka diperoleh tingkat kepuasan masyarakat kinerja penyediaan sarana umum variabel kemampuan dengan nilai indeks kepuasan masyarakat (IKM) yaitu 68,01 dengan kinerja baik. Hasil pengukuran kinerja menunjukkan bahwa kemampuan sarana umum yang terdapat di kawasan Panakukang Mas dari keterjangkauan transportasi, jarak, dan waktunya dan fisik sarana umum memadai untuk digunakan.

\section{c. Variabel Jaminan}

Variabel jaminan sarana umum mengukur kemampuan pelayanan publik yang responsif, transparan, dan akuntabel, memiliki kemudahan mengakses pelayanan informasi, berdasarkan indikator informasi pelayanan sarana umum dan tingkat pemeliharaan sarana umum di kawasan Panakukang Mas, hasil pengukuran kinerja variabel jaminan sarana umum diperoleh tingkat kepuasan masyarakat variabel jaminan diperoleh nilai indeks kepuasan masyarakat (IKM) yaitu 66,06 dengan kinerja pelayanan baik. Pengukuran kinerja penyediaan variabel jaminan sarana umum menunjukkan bahwa sarana umum dapat dikatakan terjamin keberadaannya di kawasan Panakukang Mas dari informasi yang diberikan dan pemeliharaan yang dilaksanakan untuk kontinuitas penggunaan layanan sarana umum.

\section{d. Variabel Kelayakan}

Variabel kelayakan sarana umum merupakan variabel yang menilai kelayakan penyediaan sarana umum berdasarkan indikator kemampuan menyediakan pelayanan sarana umum dan pemeliharaan atau pengelolaan sarana umum itu sendiri. Hasil pengukuran kinerja variabel kelayakan sarana umum diperoleh tingkat kepuasan masyarakat dengan nilai indeks IKM yaitu 71,44 atau kinerja pelayanan baik. Pengukuran kinerja penyediaan variabel kelayakan sarana umum, menunjukkan kelayakan keberadaan sarana umum di kawasan Panakukang Mas, dengan dua indikator yaitu penyediaan sarana umum dan pemeliharaan sarana umum.

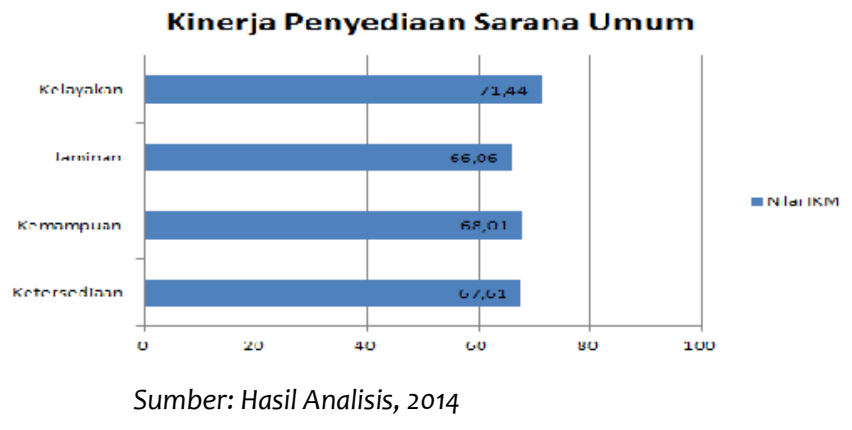

GAMBAR 4

KINERJA PENYEDIAAN SARANA UMUM

\section{Analisis Penyebab Kinerja Pelayanan Sarana Umum Kawasan Panakukang Mas Berdasarkan} Pendapat Masyarakat Pengguna

Analisis penyebab kinerja pelayanan sarana umum merupakan pengukuran kinerja pelayanan sarana umum dengan menggunakan indeks kepuasan masyarakat (IKM) dan pendapat responden pengguna sarana umum kawasan Panakukang Mas, hasil pengukuran yang didapatkan akan menunjukkan tingkat kepuasan masyarakat terhadap penyelenggara atau pemberi pelayanan apakah sesuai harapan dan kebutuhan masyarakat. Pengukuran pelayanan sarana umum dengan survei kuesioner berdasarkan variabel efektifitas pelayanan, variabel efisiensi pelayanan, variabel responsivitas pelayanan, dan variabel kecukupan pelayanan. 
Untuk pengukuran lebih rinci akan dijelaskan berdasarkan variabel-variabel kinerja pelayanan sarana umum sebagai berikut:

\section{a. Variabel Efektifitas}

Variabel efektifitas pelayanan mengukur sejauhmana kinerja pelayanan pemerintah sebagai penyelenggara pelayanan publik mencapai hasil yang diharapkan, berdasarkan indikator prosedur pelayanan, persyaratan pelayanan, kejelasan dan kepastian petugas pelayanan, dan kedisiplinan petugas pelayanan yang merupakan penyebab kinerja variabel efektifitas. Hasil pengukuran kinerja variabel efektifitas pelayanan sarana umum diperoleh tingkat kepuasan masyarakat melalui indeks kepuasan masyarakat (IKM) variabel efektifitas yaitu nilai 69,11 dengan kinerja baik. Efektifitas pelayanan dapat terintegrasi melalui pelayanan terpadu satu atap yaitu pola pelayanan yang diselenggarakan dalam satu tempat yang menjadi pilihan tepat karena tidak mempunyai keterkaitan proses dan tidak dilayani melalui beberapa pintu.

\section{b. Variabel Efisiensi}

Variabel efisiensi pelayanan mengukur tingkat kepuasan masyarakat terhadap pelayanan sarana umum berkenaan dengan jumlah usaha yang dibutuhkan dalam menghasilkan tingkat efektifitas yang diharapkan. Variabel efisiensi pelayanan diukur berdasarkan indikator tanggung jawab petugas, kemampuan petugas memberikan pelayanan, kecepatan penanganan pelayanan, keadilan mendapatkan pelayanan yang merupakan penyebab kinerja efisiensi. Untuk hasil pengukuran kinerja variabel efisiensi pelayanan sarana umum diperoleh penilaian tingkat kepuasan masyarakat terhadap kinerja pelayanan dengan indeks kepuasan masyarakat (IKM) 69,11 dengan kinerja pelayanan baik. Melalui variabel efisiensi pelayanan akan diketahui seberapa besar usaha yang dilakukan dapat merubah harapan menjadi kondisi yang diharapkan.

\section{c. Variabel Responsivitas}

Variabel responsivitas pelayanan berkenaan dengan ukuran seberapa jauh kebijakan (pelayanan yang dilaksanakan) dapat memberikan kebutuhan, preferensi atau nilai kepada masyarakat pengguna. Indikatornya kesopanan dan keramahan petugas dalam pelayanan, kewajaran mendapatkan biaya, kesesuaian biaya pelayanan, dan ketepatan jadwal pelayanan. Hasil pengukuran yang dilakukan terhadap kinerja variabel responsivitas pelayanan sarana umum diperoleh nilai kepuasan masyarakat terhadap kinerja responsivitas pelayanan sarana umum dengan indeks kepuasan masyarakat 68,24 dan kinerja pelayanan baik. Dalam variabel responsivitas pelayanan pengukuran kinerja melihat hal penting yaitu standar dan biaya yang terkait.

\section{d. Variabel Kecukupan}

Variabel kecukupan pelayanan merupakan variabel yang mengukur seberapa nyaman dan aman pelayanan dapat dilaksanakan. Indikator variabel ini mencakup kenyamanan lingkungan tempat pelayanan dan keamanan selama pelayanan berlangsung pada sarana umum kawasan Panakukang Mas. Untuk hasil pengukuran kinerja diperoleh nilai tingkat kepuasan masyarakat terhadap kecukupan pelayanan sarana umum dengan nilai indeks kepuasan masyarakat (IKM) adalah 74,80 dengan kinerja pelayanan baik. Secara keseluruhan untuk pelayanan sarana umum, variabel kecukupan pelayanan menunjukkan nilai indeks kepuasan konsumen (IKM) tertinggi dari variabel lainnya yaitu 74,80 , hal ini memang karena kawasan ini relatif aman karena tersebarnya pos pengamanan dan lokasi kantor polisi sektor Panakkukang di Panakukang Mas sebagai jaminan keamanan. Dalam 
variabel kecukupan pelayanan pengukuran kinerja menggunakan indikator kenyamanan lingkungan dan keamanan lingkungan tempat pelayanan.

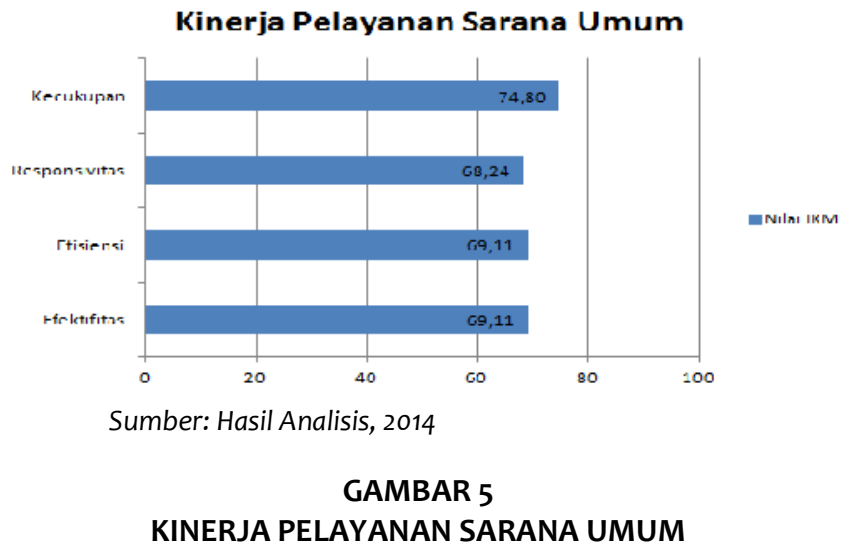

\section{KESIMPULAN}

Dapat disimpulkan bahwa Panakukang Mas sebagai kawasan permukiman terpadu di Kota Makassar merupakan kawasan yang diarahkan untuk pengembangan permukiman modern dengan identitas sebagai pusat perdagangan dan niaga serta perumahan, untuk itu perlu didukung fasilitas penunjang kegiatan masyarakat yaitu sarana umum kawasan yang memadai. Persebaran sarana umum dikawasan Panakukang perlu meninjau penyediaan sarana umum dengan melihat lokasi dan kebutuhan masyarakat. Hasil analisis dapat menunjukkan bahwa kebijakan pelayanan dan penyediaan sarana umum baik sehingga secara umum dengan pengukuran indeks kepuasan masyarakat (IKM) menunjukkan kinerja baik. Ukuran kinerja melalui indeks kepuasan masyarakat menunjukkan pelayanan di kawasan Panakukang Mas sudah baik walaupun beberapa pendapat responden dalam indikator variabel penyediaan dan pelayanan masih ada yang kurang seperti indikator kecepatan pelayanan, kesesuaian dan ketepatan jadwal pelayanan.

\section{DAFTAR PUSTAKA}

BPS Kota Makassar. 2013. Kecamatan Panakkukang dalam Angka. http://makassarkota.bps.go.id/index.php?hal=publikasi_detil\&id=49. Diakses pada tanggal 20 Maret 2014.

Dwiyanto. 2008. Mewujudkan Good Governance Melalui Pelayanan Publik. Yogyakarta: Penerbit Gadjah Mada University Press.

Elis, A.M. and Bianca Enescu. 2013. "Good Local Public Administration and Performance. An Empirical Study". Procedia-Social and Behavioral Sciences, Vol. 81, pp. 449-453.

Jones, W. 2001. Organizational Behavior a Global Perspectives. Australia: Sons \& Zulian Yamit.

Keputusan Menteri Pendayagunaan Aparatur Negara Nomor: Kep/25/M.PAN/2/2004 tentang Indeks Kepuasan Masyarakat.

Kotler, Philip. 2007. Manajemen Pemasaran Edisi 12 Jilid I. Jakarta: Penerbit PT. Indeks.

Maleki, M.Z. \& Zain. 2011. “ Factors That Influence Distance to Facilities in A Sustainable Efficient Residential Site Design. Sustainable Cities and Society, Vol. 1, pp. 236-243. 
Monkkonen, Paavo. 2013. "Urban Land-Use Regulations and Housing Markets in Developing Countries: Evidence From Indonesia on the Importance of Enforcement." Land Use Policy, Vol. 34, pp. 255-264.

Neutensa, T. 2012. "An Analysis of Day-to-day Variations in Individual Space-time Accessibility." Journal of Transport Geography, Vol. 23, pp. 81-91.

Nugroho, Riant. 2009. Public Policy. Jakarta: Penerbit Elex Media Komputindo.

Rencana Tata Ruang Wilayah Kota Makassar 2005-2015. Badan Perencanaan Pembangunan Daerah Kota Makassar, 2013.

Situmorang, M. Victor, 1994. Aspek Hukum Pengawasan Melekat Dalam Lingkungan Aparatur Pemerintah. Jakarta: Penerbit Rineka Cipta.

Suryokusumo, Anggoro. 2008. Pelayanan Publik dan Pengelolaan Infrastruktur Perkotaan. Yogyakarta: Penerbit Sinergi. 